\title{
Copper-Catalyzed Amination of Vinyl Azides to $\alpha$-Ketoamides
}

\author{
Yu Wang a \\ Dongling Zhang ${ }^{a}$ \\ Kaining Zhang ${ }^{\text {b }}$ \\ Zhenhua Liu*b \\ Jing Lin ${ }^{a}$ \\ Wei Cao ${ }^{a}$ \\ Zhongxue Fang*a (D) \\ a School of Chemistry and Environmental Engineering, \\ Yancheng Teachers University, Yancheng224007, \\ P. R. of China \\ fangzhongxue120@163.com \\ ${ }^{b}$ College of Chemistry, Chemical Engineering and Materials \\ Science, Shandong Normal University, Jinan 250014, \\ P. R. of China \\ liuzhenhua2012@163.com
}

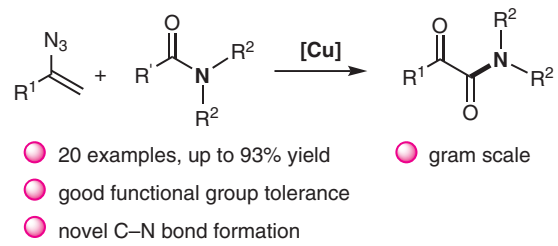

which were successfully transformed into a series of $\alpha$ functionalized ketones (Scheme 1c). ${ }^{8}$ However, with respect to the construction of $\alpha$-functionalized ketones, these methods usually suffer from disadvantages such as tedious multistep operations or harsh conditions. In a continuation of our efforts on the construction of $\mathrm{C}-\mathrm{N}$ bond reactions, ${ }^{9}$ we herein report a novel radical amination of vinyl azides using a copper catalyst, to afford a series of $\alpha$-ketoamides (Scheme 1). To our knowledge, this is the first example of the conversion of vinyl azides into $\alpha$-ketoamides, which are important units in biologically active molecules, synthetic drugs, and drug candidates. ${ }^{10}$

An efficient approach for the amination of vinyl azides with $\mathrm{N}, \mathrm{N}$-dialkylacylamides has been developed. By using this protocol, structurally important $\alpha$-ketoamides can be easily synthesized. The key to success is not only the introduction of a $\mathrm{Cu}(\mathrm{I}) /$ oxygen catalytic system but also the utilization of $t$-BuOCl and benzoic acid as additives. The reaction is operationally simple, scalable, and displays broad scope and functional group tolerance. A possible mechanism involving copper-catalyzed oxidative generation of peroxide radicals is proposed.

Key words amination, $\alpha$-ketoamide, vinyl azide, copper-catalysis, $\mathrm{N}, \mathrm{N}$-dialkylacylamides

Vinyl azides are a class of unique functionalized alkenes with high intrinsic reactivity. ${ }^{1}$ The numerous transformations of vinyl azides provide reliable synthetic approaches to diverse, structurally distinct molecular frameworks, including hetero/carbocycles, ${ }^{2}$ amides, ${ }^{3}$ ketones, ${ }^{4}$ and $2 \mathrm{H}$ azirines. ${ }^{5}$ Recently, Wu and Liu $^{6}$ described an efficient and mild method for the synthesis of various $\alpha$-fluoroketones from the corresponding vinyl azides by using Selectfluor ${ }^{\circledR}$ as the fluorine source (Scheme 1a). Additionally Chiba ${ }^{7}$ and $\mathrm{Liu}^{4 \mathrm{a}}$ respectively, disclosed radical trifluoromethylation of vinyl azides with $\mathrm{Me}_{3} \mathrm{SiCF}_{3}$, to allow construction of $\alpha$-trifluoromethyl azines, which could be further converted into $\alpha$-trifluoromethyl ketones (Scheme $1 \mathrm{~b}$ ). Bi and co-workers presented a radical-induced enamination of vinyl azides that proceeded with electron-withdrawing substrates, and a variety of $\beta$-functionalized primary enamines, including $\beta$-nitro, acyl, and sulfonyl derivatives, could be prepared,
Previous Work

(a)

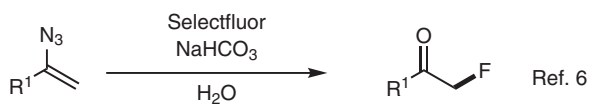

(b)

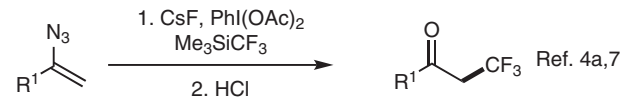

(c)

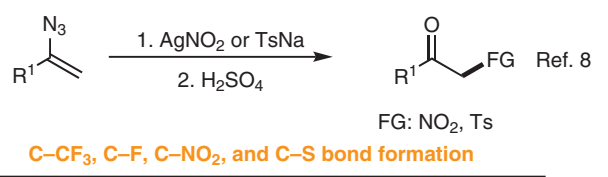

This Work

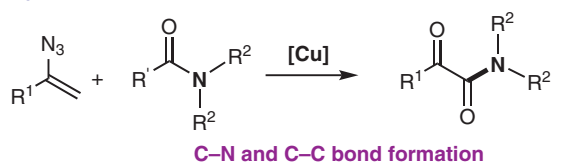

Scheme 1 Transformations of vinyl azides

For the optimization of the reaction conditions, we carried out the reaction of vinyl azide $\mathbf{1 a}$ and $N, N$-dimethylformamide (DMF; 2a), as model substrates for the amination 
reaction, to screen different catalysts, solvents and additives (Table 1). Firstly, when CuI was used as the catalyst in DMF as the solvent at $100^{\circ} \mathrm{C}$ for $5 \mathrm{~h}$ under an oxygen atmosphere, the corresponding $\alpha$-ketoamide 3a was obtained in $67 \%$ yield (entry 1 ). Using $\mathrm{CuBr}$ as the catalyst also gave a comparable yield under similar conditions (entry 2). Other metal catalysts, such as $\mathrm{CuCl}_{2}, \mathrm{NiCl}_{2}$, or $\mathrm{Ag}_{2} \mathrm{CO}_{3}$, gave either low yields or trace amounts of the desired product $\mathbf{3 a}$ (entries 3-5). Subsequent solvent screening demonstrated that DMF was the best choice; solvents, such as toluene, ethylene glycol, and nitromethane resulted in no desired product (entries 6-8). The use of additives, such as $m$-CPBA, TBHP or BPO, did not improve the efficiency of the reaction (entries 9-11). However, the addition of acids $\left(\mathrm{HBF}_{4}\right.$ or benzoic acid) did improve the efficiency of the reaction, affording 3a in $70 \%$ and $88 \%$ yields, respectively (entries 12 and 13). The reaction failed to occur in the absence of either the catalyst or additive (entries 14 and 15).

Table 1 Optimization of the Reaction Conditions ${ }^{\mathrm{a}}$

\begin{tabular}{|c|c|c|c|c|}
\hline & 1a & $2 a$ & & 3a \\
\hline Entry & Catalyst & Solvent & Additive & Yield (\%) \\
\hline 1 & Cul & DMF & $t-\mathrm{BuOCl}$ & 67 \\
\hline 2 & $\mathrm{CuBr}$ & DMF & $t$-BuOCl & 56 \\
\hline 3 & $\mathrm{CuCl}_{2}$ & DMF & $t-\mathrm{BuOCl}$ & trace \\
\hline 4 & $\mathrm{NiCl}_{2}$ & DMF & $t$-BuOCl & 19 \\
\hline 5 & $\mathrm{Ag}_{2} \mathrm{CO}_{3}$ & DMF & $t$-BuOCl & 20 \\
\hline 6 & Cul & toluene & $t$-BuOCl & 0 \\
\hline 7 & Cul & EG & $t-\mathrm{BuOCl}$ & 0 \\
\hline 8 & Cul & $\mathrm{MeNO}_{2}$ & $t-\mathrm{BuOCl}$ & 0 \\
\hline 9 & Cul & DMF & $m$-CPBA & 26 \\
\hline 10 & Cul & DMF & TBHP & 53 \\
\hline 11 & Cul & DMF & $\mathrm{BPO}$ & 38 \\
\hline 12 & Cul & DMF & $t-\mathrm{BuOCl}+\mathrm{HBF}_{4}^{\mathrm{c}}$ & 70 \\
\hline 13 & Cul & DMF & $t-\mathrm{BuOCl}+\mathrm{PhCO}_{2} \mathrm{H}^{\mathrm{c}}$ & 88 \\
\hline 14 & - & DMF & $t-\mathrm{BuOCl}+\mathrm{PhCO}_{2} \mathrm{H}^{\mathrm{c}}$ & 0 \\
\hline 15 & Cul & DMF & - & 0 \\
\hline
\end{tabular}

a Reaction conditions: 1 a $(0.5 \mathrm{mmol}), \mathbf{2 a}(0.75 \mathrm{mmol})$, catalyst $(0.15$ $\mathrm{mmol})$, solvent $(1.0 \mathrm{~mL})$, additive $(1.0 \mathrm{mmol}), \mathrm{O}_{2}$ atmosphere, $100^{\circ} \mathrm{C}, 5 \mathrm{~h}$. ${ }^{\mathrm{b}}$ Isolated yield.

${ }^{\mathrm{C}}$ Acid $(1.0 \mathrm{mmol})$.

With the optimized reaction conditions in hand (Table 1 , entry 13), the generality of this $\alpha$-ketoamide synthesis was examined by using a series of vinyl azides to react with DMF (Scheme 2). $\alpha$-Aryl-substituted vinyl azides were readily transformed into the corresponding $\alpha$-ketoamides $3 \mathbf{a}-\mathbf{n}$ in moderate to excellent yields. Electron-donating groups in the para-position of the aromatic ring were well tolerated, leading to the corresponding products $3 \mathbf{a}-\mathbf{e}$ in good to excellent yields. Likewise, vinyl azides possessing aryl substituents bearing electron-withdrawing groups, such as $-\mathrm{F},-\mathrm{Cl}$, $-\mathrm{Br}$, $-\mathrm{CHO}$, and $-\mathrm{CO}_{2} \mathrm{Me}$, afforded the desired $\alpha$-ketoamides 3f-j in $79-90 \%$ yield. Note that vinyl azides bearing heteroaromatic substituents such as thienyl could be smoothly incorporated onto $\alpha$-ketoamide $3 \mathbf{k}$ in $88 \%$ yield. Moreover, vinyl azide derivatives bearing a variety of substitutions in the meta-position of the aryl ring, including both electrondonating and electron-withdrawing groups, were well tolerated; thereby affording the functionalized $\alpha$-ketoamides 31-n in $69-87 \%$ yields.

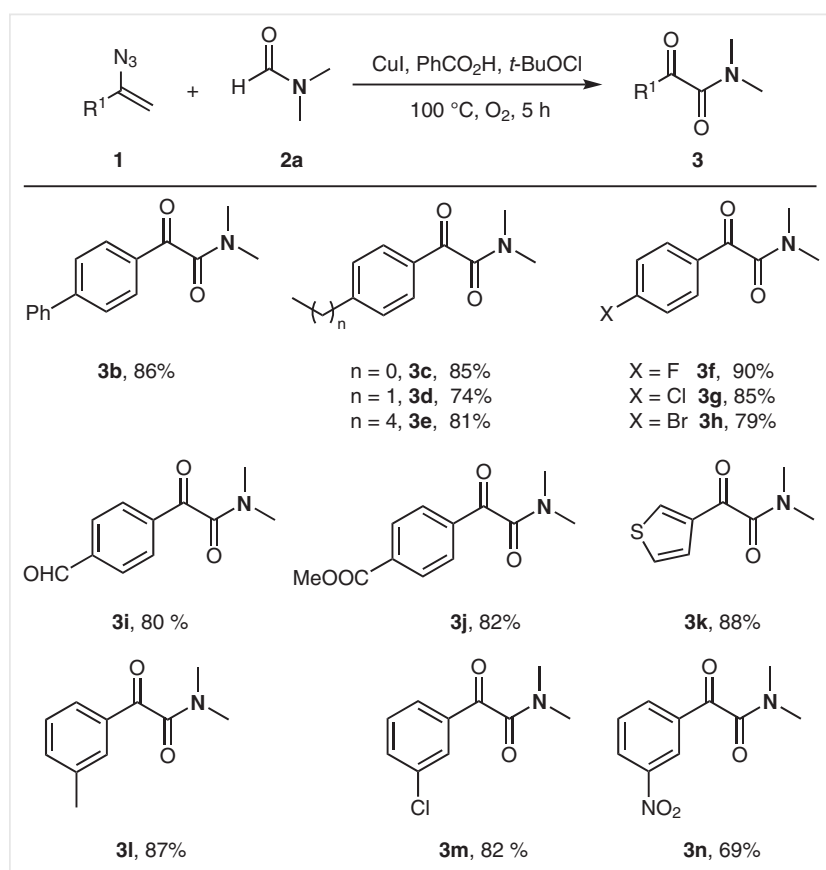

Scheme 2 Substrate scope for the reaction of vinyl azides with DMF (used as both solvent and reactant)

To investigate the applicability of this protocol further, $N, N$-diethyl- $\alpha$-ketoamide products $\mathbf{4 a - f}$ were prepared using vinyl azides $\mathbf{1}$ and $N, N$-diethylformamide (2b) as the substrates under the optimized conditions (Scheme 3). Vinyl azides 1a-f with aromatic substituents, including aryl and heteroaryl groups, underwent the reaction smoothly to give the desired products $\mathbf{4 a - f}$ in $77-93 \%$ yield.

Encouraged by these results, we next turned our attention to other representative nitrogen sources (Table 2). Indeed, not only DMF (2a) and $N, N$-diethylformamide (2b) but also $\mathrm{N}, \mathrm{N}$-dimethylacetamide (DMA) and $\mathrm{N}, \mathrm{N}$-dimethylpropylamide (DMP) were tolerated under the standard conditions, with the resultant $\alpha$-ketoamide products being obtained in slightly lower yields (entries 1-4). In addition, the long chain $N, N$-dimethylbutylamide (DMB) was also examined, although no desired product was detected (entry 5). 


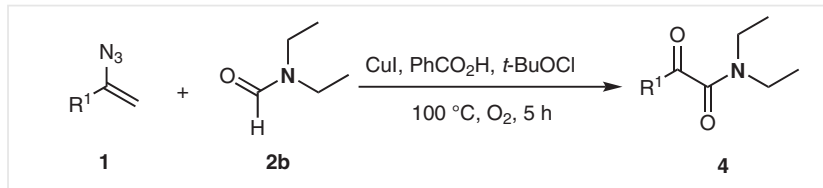<smiles>CCN(CC)C(=O)C(=O)c1ccccc1</smiles>

4a, $77 \%$<smiles>CCN(CC)C(=O)C(=O)c1cccc(C)c1</smiles>

$4 b, 87 \%$<smiles>CCN(CC)C(=O)C(=O)c1ccc(C(C)=O)cc1</smiles>

4d, $93 \%$<smiles>CCN(CC)C(=O)C(=O)c1ccc(Cl)cc1</smiles>

$4 e, 81 \%$

Scheme 3 Substrate scope for the reaction of vinyl azides with $\mathrm{N}, \mathrm{N}$-diethylformamide. Reaction conditions: $\mathbf{1}(0.5 \mathrm{mmol}), \mathbf{2}(1.0 \mathrm{~mL})$, Cul (0.15 mmol), $\mathrm{PhCO}_{2} \mathrm{H}(1.0 \mathrm{mmol}), t$ - $\mathrm{BuOCl}(1.0 \mathrm{mmol}), \mathrm{O}_{2}$ atmosphere, $100{ }^{\circ} \mathrm{C}, 5 \mathrm{~h}$.

Table 2 Substrate Scope for the Reaction of Vinyl Azides with N,N-Dimethyl Substrates ${ }^{\mathrm{a}}$

$$
\text { Entry }
$$

\begin{tabular}{|c|c|c|c|}
\hline Entry & Substrate & Product & Yield (\%) \\
\hline
\end{tabular}

a Reaction conditions: $1(0.5 \mathrm{mmol}), 2(1.0 \mathrm{~mL}), \mathrm{Cul}(0.15 \mathrm{mmol}), \mathrm{PhCO}_{2} \mathrm{H}$ $(1.0 \mathrm{mmol}), t$-BuOCl $(1.0 \mathrm{mmol}), \mathrm{O}_{2}$ atmosphere, $100^{\circ} \mathrm{C}, 5 \mathrm{~h}$. $\mathrm{b}$ Isolated yield.<smiles>CCN(CC)C(=O)C(=O)c1ccsc1</smiles>

4c, $91 \%$

To elucidate a plausible reaction mechanism for this transformation, some potential intermediates were prepared and tested under the standard conditions (Table 1 , entry 13). Vinyl azide 1a' did not afford benzamide 3a under the standard conditions (Scheme 4a), although 3-phenyl-2H-azirine ( $\left.\mathbf{1} \mathbf{b}^{\prime}\right), N$-(1-phenylvinyl)acetamide $\left(\mathbf{1} \mathbf{c}^{\prime}\right)$, and 2-chloro-1-phenylethan-1-one (1 $\left.\mathbf{d}^{\prime}\right)$ all afforded 3a in good yields (Scheme 4b-d). 2-(Diethylamino)-1-phenylethan-1one $\left(\mathbf{1}^{\prime}\right)$ did not react under the standard conditions (Scheme 4e), ${ }^{11}$ nor did dimethylamine (2a'; Scheme 4f). Interestingly, the addition of the radical scavengers 2,2,6,6-tetramethylpiperidine-1-oxyl (TEMPO) or 2,6-di-tert-butyl$p$-cresol (BHT) suppressed the reaction, which indicates that free radical intermediates could be involved in this transformation (Scheme $4 \mathrm{~g}$ ). Notably, only $20 \%$ yield of $\mathbf{3 a}$ was observed under an argon atmosphere, suggesting that oxygen is required to oxidize the catalyst in preparation for another cycle (Scheme 4g). These control experiments indicate that the vinyl azide substrate possibly reacts with the $t$ - $\mathrm{BuOCl}$ as the electrophile and then undergoes oxidation catalyzed by the $\mathrm{Cu} / \mathrm{O}_{2}$ system. (a)<smiles>C/C=C(/N)c1ccccc1</smiles>

$1 a^{\prime}$

(b)<smiles>c1ccc(C2=NC2)cc1</smiles>

(c)

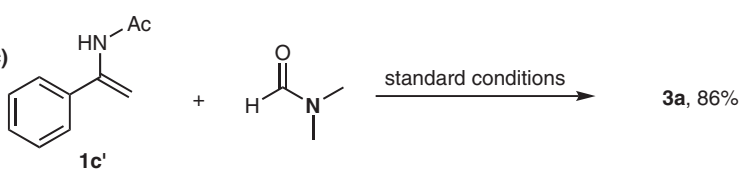

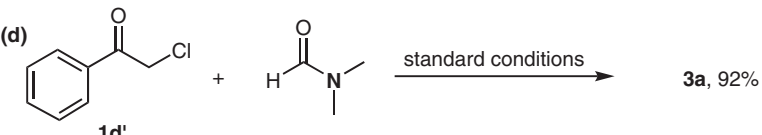

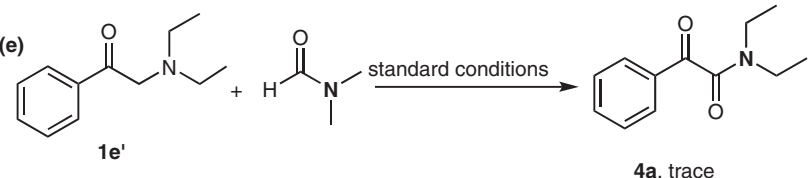

.<smiles>C=C(N)c1ccccc1</smiles><smiles>CNC(=O)N(C)C</smiles>

standard conditions

3a, trace 
According to previous reports and considering the above results, ${ }^{2 e, 12}$ a possible mechanism for this amination reaction is proposed in Scheme 5. Initially, the vinyl azide 1a undergoes thermal decomposition into a highly strained three-membered cyclic imine $(2 \mathrm{H}$-azirine $\mathbf{A})$ that reacts with the $\mathrm{Cu}(\mathrm{I})$ catalyst and $t-\mathrm{BuOCl}$ to form $\mathrm{Cu}(\mathrm{II})$ imine $\mathbf{B}$, which is then converted into $\mathrm{Cu}(\mathrm{II})$ imine $\mathbf{C} .^{2 e, 13}$ Radical intermediate $\mathbf{E}$ would be formed via $\mathrm{Cu}(\mathrm{III})$ peroxide radical D, which could be generated by a combination of molecular oxygen with $\mathrm{Cu}(\mathrm{II})$ imine $\mathbf{C}$. Subsequent reductive elimination of radical intermediate $\mathbf{E}$ gives intermediate $\mathbf{F}$ and regenerates the active $\mathrm{Cu}(\mathrm{I})$ species. Finally, $\alpha$-ketoamide $\mathbf{3 a}$ is obtained through acid hydrolysis of intermediate $\mathbf{F}$.

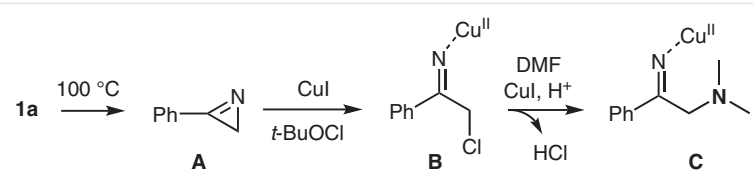

$$
\begin{aligned}
& \text { 年 }
\end{aligned}
$$

Scheme 5 Proposed mechanism

The potential synthetic applicability of this method was investigated on a gram scale by using the model reaction. As shown in Scheme 6, $1.54 \mathrm{~g}$ of $\alpha$-ketoamide 3a was isolated in $87 \%$ yield without any significant loss of efficiency, demonstrating the potential of this methodology for largescale synthesis of $\alpha$-ketoamide derivatives.

$$
\text { 1a (10 mmol) } \quad \underset{2 a(15 \mathrm{~mL})}{\stackrel{\mathrm{Cul}, \mathrm{PhCO}_{2} \mathrm{H}, t-\mathrm{BuOCl}}{100^{\circ} \mathrm{C}, \mathrm{O}_{2}, 5 \mathrm{~h}}}
$$

Scheme 6 Gram-scale experiment

In conclusion, we have developed a general and efficient method for the synthesis of $\alpha$-ketoamides from vinyl azides with $\mathrm{N}, \mathrm{N}$-dialkylacylamide as the nitrogen source. ${ }^{14}$ The key to success is not only the introduction of a $\mathrm{Cu} / \mathrm{O}_{2}$ catalytic system but also the use of $t$ - $\mathrm{BuOCl}$ and benzoic acid as additives. This method features readily accessible substrates, commercially available and inexpensive reagents, and mild conditions. This mild catalytic reaction demonstrates a broad substrate scope and high functional group tolerance. A possible mechanism involving copper-catalyzed oxidative generation of peroxide radicals is proposed. The reaction can be effectively scaled up and the product conveniently obtained in a one-pot process. Efforts to further clarify the mechanism and to expand the application of vinyl azides are under way in our laboratory.

\section{Funding Information}

The authors wish to thank the National Natural Science Foundation of China (21605097), the Natural Science Foundation of Shandong Province of China (ZR2016BQ01), the China Postdoctoral Science Foundation (2017M610442), and The Natural Science Foundation of the Jiangsu Higher Education Institutions of China (18KJB610021).

\section{References and Notes}

(1) For recent progress in the synthesis of vinyl azides, see: (a) Liu, Z.; Liu, J.; Zhang, L.; Liao, P.; Song, J.; Bi, X. Angew. Chem. Int. Ed. 2014, 53, 5305. (b) Liu, Z.; Liao, P.; Bi, X. Org. Lett. 2014, 16, 3668.

(2) (a) Lopez, E.; Lopez, L. Angew. Chem. Int. Ed. 2017, 56, 5121. (b) Shu, W.; Lorente, A.; Gómez-Bengoa, E.; Nevado, C. Nat. Commun. 2017, 8, 13832. (c) Wang, Y.-F.; Toh, K. K.; Ng, E. P. J.; Chiba, S. J. Am. Chem. Soc. 2011, 133, 6411. (d) Wang, Y.-F.; Chiba, S. J. Am. Chem. Soc. 2009, 131, 12570. (e) Wang, Y.-F.; Toh, K. K.; Lee, J.-Y.; Chiba, S. Angew. Chem. Int. Ed. 2011, 50, 5927.

(3) (a) Lin, C.; Shen, Y.; Huang, B.; Liu, Y.; Cui, S. J. Org. Chem. 2017, 82, 3950. (b) Zhang, Z.; Kumar, R. K.; Li, G.; Wu, D.; Bi, X. Org. Lett. 2015, 17, 6190. (c) Zhang, F.-L.; Wang, Y.-F.; Lonca, G. H.; Zhu, X.; Chiba, S. Angew. Chem. Int. Ed. 2014, 53, 4390. (d) Qin, C.; Feng, P.; Ou, Y.; Shen, T.; Wang, T.; Jiao, N. Angew. Chem. Int. Ed. 2013, 52, 7850.

(4) (a) Qin, H.-T.; Wu, S.-W.; Liu, J.-L.; Liu, F. Chem. Commun. 2017, 53, 1696. (b) Chen, W.; Liu, X.; Chen, E.; Chen, B.; Shao, J.; Yu, Y. Org. Chem. Front. 2017, 4, 1162.

(5) (a) Xu, H.-D.; Zhou, H.; Pan, Y.-P.; Ren, X.-T.; Wu, H.; Han, M.; Han, R.-Z.; Shen, M.-H. Angew. Chem. Int. Ed. 2016, 55, 2540. (b) Farney, E. P.; Yoon, T. P. Angew. Chem. Int. Ed. 2014, 53, 793.

(6) Wu, S.-W.; Liu, F. Org. Lett. 2016, 18, 3642.

(7) Wang, Y.-F.; Lonca, G. H.; Chiba, S. Angew. Chem. Int. Ed. 2014, 53, 1067.

(8) Ning, Y.; Zhao, X.-F.; Wu, Y.-B.; Bi, X. Org. Lett. 2017, 19, 6240.

(9) (a) Wang, Y.; Wei, C.; Tang, R.; Zhan, H.; Lin, J.; Liu, Z.; Tao, W.; Fang, Z. Org. Biomol. Chem. 2018, 16, 6191. (b) Fang, Z.; Feng, Y.; Dong, H.; Li, D.; Tang, T. Chem. Commun. 2016, 52, 11120. (c) Liu, J.; Fang, Z.; Zhang, Q.; Liu, Q.; Bi, X. Angew. Chem. Int. Ed. 2013 , 125, 7091. (d) Fang, Z.; Yuan, H.; Liu, Y.; Tong, Z.; Li, H.; Yang, J.; Barry, B.-D.; Liu, J.; Liao, P.; Zhang, J.; Liu, Q.; Bi, X. Chem. Commun. 2012, 48, 8802. (e) Wang, K.; Bi, X.; Xing, S.; Liao, P.; Fang, Z.; Meng, X.; Zhang, Q.; Liu, Q.; Ji, Y. Green Chem. 2011, 13, 562.

(10) (a) Blackburn, E. A.; Walkinshaw, M. D. Curr. Opin. Pharmacol. 2011, 11, 365. (b) Álvarez, S.; Álvarez, R.; Khanwalkar, H.; Germain, P.; Lemaire, G.; Rodríguez-Barrios, F.; Gronemeyer, H.; de Lera, A. R. Bioorg. Med. Chem. 2009, 17, 4345. (c) Avolio, S.; Robertson, K.; Hernando, J. I. M.; DiMuzio, J.; Summa, V. Bioorg. Med. Chem. Lett. 2009, 19, 2295. (d) Knust, H.; Nettekoven, M.; Pinard, E.; Roche, O.; Rogers-Evans, M. PCT Int. Appl. WO 2009016087, 2009. (e) Njoroge, F.; Chen, K. X.; Shih, N.-Y.; Piwinski, J. J. Acc. Chem. Res. 2008, 41, 50. (f) De Clercq, E. Nat. Rev. Drug Discovery 2007, 6, 1001.

(11) Liang, S.; Zeng, C.-C.; Tian, H.-Y.; Sun, B.-G.; Luo, X.-G.; Ren, F.-Z. J. Org. Chem. 2016, 81, 11565.

(12) (a) Hayashi, H.; Kaga, A.; Chiba, S. J. Org. Chem. 2017, 82, 11981. (b) Liu, H.; Feng, M.; Jiang, X. Chem. Asian J. 2014, 9, 3360. (c) Ding, S.; Jiao, N. Angew. Chem. Int. Ed. 2012, 51, 9226. (d) Liu, Z.-Q.; Zhao, L.; Shang, X.; Cui, Z. Org. Lett. 2012, 14, 3218. (e) Rolff, M.; Schottenheim, J.; Decker, H.; Tuczek, F. Chem. Soc. 
Rev. 2011, 40, 4077. (f) Too, P. C.; Chua, S. H.; Wong, S. H.; Chiba, S. J. Org. Chem. 2011, 76, 6159. (g) Chiba, S.; Zhang, L.; Ang, G. Y.; Hui, B. W.-Q. Org. Lett. 2010, 12, 2052. (h) Que, L. J.; Tolman, W. B. Nature 2008, 455, 333. (i) Cramer, C. J.; Tolman, W. B. Acc. Chem. Res. 2007, 40, 601. (j) Arends, I.; Gamez, P.; Sheldon, R. A. Adv. Inorg. Chem. 2006, 58, 235. (k) Mirica, L. M.; Vance, M.; Rudd, D. J.; Hedman, B.; Hodgson, K. O.; Solomon, E. I.; Stack, T. D. P. Science 2005, 308, 1890. (1) Prigge, S. T.; Eipper, B. A.; Mains, R. E.; Amzel, L. M. Science 2004, 304, 864. (m) Wang, Y.; DuBios, J. L.; Hedman, B.; Hodgson, K. O.; Stack, T. D. P. Science 1998, 279, 537. (n) Manis, P. A.; Rathke, M. W. J. Org. Chem. 1980, 45, 4952.

(13) Fu, J.; Zanoni, G.; Anderson, E. A.; Bi, X. Chem. Soc. Rev. 2017, 46, 7208.

(14) Synthesis of 4a; Typical Procedure: To a solution of $\alpha$-azido styrene (1a; $72.5 \mathrm{mg}, 0.5 \mathrm{mmol}$ ), tert-butyl hypochlorite (113.1 $\mu \mathrm{L}, 1.0 \mathrm{mmol}$ ), and benzoic acid (122.1 $\mathrm{mg}, 1.0 \mathrm{mmol}$ ) in $\mathrm{N}, \mathrm{N}-$ diethylformamide $(\mathbf{2 b} ; 1 \mathrm{~mL})$ at room temperature, CuI (28.6 $\mathrm{mg}, 0.15 \mathrm{mmol}$ ) was added. The reaction mixture was heated at $100{ }^{\circ} \mathrm{C}$ and stirred for $5 \mathrm{~h}$ under an oxygen atmosphere, when TLC analysis confirmed that substrate 1a had been consumed. The resulting reaction mixture was cooled to room temperature and $\mathrm{K}_{2} \mathrm{CO}_{3}$ was added. The mixture was extracted with dichloromethane $(3 \times 15 \mathrm{~mL})$, and the combined organic extracts were washed with brine $(3 \times 40 \mathrm{~mL})$, dried over $\mathrm{MgSO}_{4}$, filtered and concentrated. Purification of the crude product by flash column chromatography (silica gel; petroleum ether) afforded $\mathbf{4 a}$ (77\% yield) as a yellow oil.

$\boldsymbol{N}, \boldsymbol{N}$-Diethyl-2-oxo-2-phenylacetamide (4a): ${ }^{1} \mathrm{H}$ NMR (400 $\left.\mathrm{MHz}, \mathrm{CDCl}_{3}\right): \delta=7.93(\mathrm{~d}, J=7.1 \mathrm{~Hz}, 2 \mathrm{H}), 7.64(\mathrm{t}, J=7.4 \mathrm{~Hz}, 1 \mathrm{H})$, $7.51(\mathrm{t}, J=7.7 \mathrm{~Hz}, 2 \mathrm{H}), 3.61-3.53(\mathrm{~m}, 2 \mathrm{H}), 3.29-3.20(\mathrm{~m}, 2 \mathrm{H})$, $1.29(\mathrm{t}, J=7.2 \mathrm{~Hz}, 3 \mathrm{H}), 1.16(\mathrm{t}, J=7.1 \mathrm{~Hz}, 3 \mathrm{H}) .{ }^{13} \mathrm{C}$ NMR $(100$ $\left.\mathrm{MHz}, \mathrm{CDCl}_{3}\right): \delta=191.5,166.7,134.5,133.2,129.6,128.9,42.0$, 38.7, 14.0, 12.8. HRMS (ESI): $m / z[\mathrm{M}+\mathrm{H}]^{+}$calcd for $\mathrm{C}_{12} \mathrm{H}_{15} \mathrm{NO}_{2}$ : 206.1181; found: 206.1142 . 